\title{
PERKAWINAN SEJENIS MENURUT HAK ASASI MANUSIA DALAM PERSPEKTIF HUKUM ISLAM
}

(The Homosex Marriage According to the Human Rights in Islamic Law Perspective)

\section{SANAWIAH}

Program Studi Al Ahwal Al Syakhsiyah Fakultas Agama Islam Universitas Muhammadiyah Palangkaraya Jl. RTA Milono Km.1,5 Palangka Raya, Kalimantan Tengah 73111

e-mail : sanaw10@yahoo.co.id

\begin{abstract}
Purpose of this study is to analyze that the homosex marriage in accordance with human rights which is just and civilized, and to determine the homosex marriage according to the marriage act and the perspective of Islamic law.

The method used is a method normative considering that this study emphasizes that the secondary data that is studying and reviewing principles, materials and positive legal principles that of the materials libraries that exist in legislation marriage law and human rights law in Indonesia.

Results from this study showed that the homosex marriage in the name of human rights it violates human rights itself. Because the rights that should be fought is right according to the nature of natural and ordained by god, since man was created in pairs regarding marriages recognized by the state is only marriages between men and women can also be seen in Article 34 paragraph (1) of the Act Number 23 Year 2006 concerning population administration.
\end{abstract}

Keywords: marriage, the homosex marriage.

\section{ABSTRAK}

Tujuan penelitian ini adalah menganalisa apakah perkawinan sejenis sesuai dengan hak asasi manusia (HAM) yang adil dan beradab, dan untuk mengetahui perkawinan sejenis menurut Undang-Undang Perkawinan dan perspektif hukum Islam.

Metode yang digunakan adalah metode yuridis normatif mengingat bahwa penelitian ini menekankan bahwa pada data sekunder yakni mempelajari dan mengkaji azas-azas, bahan-bahan dan kaidah-kaidah hukum positifnya yang dari bahan-bahan kepustakaan yang ada dalam perundang-undangan Hukum Perkawinan dan Undang-Undang HAM Indonesia.

Hasil dari penelitian ini menunjukkan bahwa pernikahan sejenis atas nama hak asasi manusia (HAM) justru melanggar HAM itu sendiri. Pasalnya, HAM yang seharusnya diperjuangkan adalah hak yang sesuai dengan kodrat alam dan digariskan tuhan, mengingat manusia telah diciptakan berpasang-pasangan. Mengenai perkawinan yang diakui oleh negara hanyalah perkawinan antara pria dan wanita juga dapat kita lihat dalam Pasal 34 ayat (1) UndangUndang Nomor 23 Tahun 2006 tentang Administrasi Kependudukan.

Kata kunci : perkawinan, perkawinan sejenis

\section{PENDAHULUAN}

Polemik pernikahan akhir-akhir ini menjadi fenomena yang sangat menarik dan menyita perhatian banyak pihak. Hal ini berawal dari keputusan Mahkamah Agung Amerika Serikat yang membolehkan pernikahan sesama jenis di seluruh wilayah Amereka Serikat yang meliputi 50 negara bagian, padahal sebelumnya hanya 37 negara bagian saja yang telah mengesahkan pernikahan sesama jenis (Republika on Line, 26 Juni 2015).

Sebagai akibat keputusan itu, beberapa figur publik di indonesia yang menjadi aktifis dari fenomena ini, mendukung dan bergembira atas putusan Mahkamah Agung Amerika Serikat tersebut. Mereka seakan menanti aturan tersebut 
juga diberlakukan di Indonesia. Walaupun sebagian besar juga menolak dan anti terhadap pernikahan sesama jenis ini.

Ade Armando seorang aktifis dan pakar komunikasi Universitas Indonesia dan Universitas Paramadina Jakarta, adalah salah satu pendukung yang cukup kontroversial dalam pernikahan sesama jenis ini. Dia mempertanyakan status haram dalam Islam terkait kelompok lesbian, gay, bisektual, dan transgender (LGBT). Dalam pandangannya perilaku LGBT dan pernikahan sejenis tidak diharamkan dalam ajaran agama Islam.

Perspektif itu kemudian menjadi permasalahan yang pelik ketika harus disandingkan dengan aturan tentang perkawinan pada Pasal 1 Undang-Undang Nomor 1 Tahun 1974. Dalam aturan tersebut jelas dan dengan tegas mengatakan bahwa perkawinan adalah ikatan lahir batin antara seorang pria dengan seorang wanita wanita sebagai suami istri dengan tujuan membentuk keluarga (rumah tangga) yang bahagia dan kekal berdasarkan Ketuhanan Yang Maha Esa.

Terbentuknya keluarga yang bahagia dalam pernikahan menjadi harapan dan tujuan luhur dalam hal ini. Harapan ini kemudian menjadi permasalahan yang muncul kemudian dengan maraknya pemberitaan di media tentang pernikahan sejenis dan membuat banyak masyarakat Islam Indonesia gerah. Kegelisahan ini terus berlanjut karena fenomena ini juga pernah muncul di zaman Nabi Luth AS. Hal ini sebagaimana tertuang Al-Qur'an Surah Al A'raf ayat 80-84.

Kajian tentang pernikahan sesama jenis dan perlindungan terhadap mereka dalam Hak
Asasi Manusia (HAM) menjadi penting mendapatkan perhatian dalam perspektif Islam sehingga dapat didudukkan dengan bijaksana dari sudut pandang agama dan kepentingan pihak-pihak tertentu. Dalam kajian ini ada beberapa poin tujuan penelitian antara lain; 1). mengetahui apakah perkawinan sejenis sesuai dengan hak asasi manusia yang adil dan beradab, dan 2). mengetahui perkawinan sejenis menurut Undang-Undang Perkawinan dan perspektif hukum Islam.

\section{KAJIAN PUSTAKA}

Pengertian Perkawinan menurut UndangUndang Nomor 1 Tahun 1974 dalam Pasal 1, memberikan definisi perkawinan sebagai berikut : "perkawinan adalah ikatan lahir batin antara seorang pria dan seorang wanita sebagai suami istri dengan tujuan membentuk keluarga (rumah tangga) yang bahagia dan kekal berdasarkan Ketuhanan Yang Maha Esa".

Amanat Perkawinan menurut UndangUndang Nomor 1 Tahun 1974 dengan tegas dipahami bahwa ikatan itu terjadi antara dua jenis kelamin yang berbeda antara laki-laki dan perempuan. Penegasan ini menjadi penting karena dalam amanat tersebut jelas UU Perkawinan ini hanya membenarkan perkawinan yang bukan sesama jenis. Mengingkari UndangUndang ini bermakna mengingkari hukum yang berlaku di Indonesia.

Adapun penikahan sesama sejenis yang sedang marak menjadi perbincangan dikenal sebangai pernikahan gay, yang dalam kajian ini lebih mengambil pengertian tentang pernikahan antara dua orang yang memiliki jenis kelamin dan/atau identitas gender. Pengakuan hukum 
pernikahan sejenis atau kemungkinan untuk melakukan pernikahan sesama jenis atau kemungkinan untuk melakukan pernikahan sesama jenis kadang-kadang disebut sebagai kesetaraan perkawinan atau pernikahan setara, terutama oleh para pendukungnya.

\section{METODOLOGI}

Metode penelitian dalam kajian ini menggunakan metode yuridis normatif. Penggunaan ini dilakukan karena alasan bahwa fokus penelitian ini menekankan pada data sekunder dengan mempelajari dan mengkaji azas-azas, bahan-bahan dan kaidah-kaidah hukum positifnya berdasarkan bahan-bahan kepustakaan yang ada dalam perundangundangan Hukum Perkawinan dan UndangUndang Hak Asasi Manusia (HAM) Indonesia.

\section{HASIL DAN PEMBAHASAN}

\section{Perspektif Perkawinan Sejenis dalam Konteks HAM yang Adil dan Beradab}

Eksistensi Hak Asasi Manusia (HAM) ada sejak manusia tercipta. Hal ini karena HAM berasal dari status seseorang sebagai manusia yang secara hakiki mendapat perlindungan dengan sebaik-baiknya. Perjuangan menegakkan HAM menjadi perhatian yang sangat besar dari berbagai pihak di dunia karena ini berkaitan dengan eksistensi manusia itu sendiri. Atas dasar inilah kemudian muncul banyak pihak yang berkepentingan menuntut hak tersebut walaupun kemudian tuntutan itu bertentangan dengan fitrahnya sebagai manusia. Salah satunya adalah Kampanye legalitas pernikahan sejenis selalu menggunakan dalih hak asasi manusia (HAM) sebagai upaya meresmikan hubungan mereka.

Upaya pihak-pihak tertentu yang menginginkan legalitas pernikahan sejenis tersebut bukan berarti juga melengggang dengan mulus tanpa adanya penolakkan walaupun menggunakan bahasa hak asasi manusia (HAM) agar mendapatkan haknya. Penentangan beberapa pihak yang tidak setuju antara lain datang dari Maneger Nasution sebagai Komisioner Komisi Nasional (Komnas) HAM yang mengaku.

"Jika suatu saat muncul usulan tersebut,
dirinya akan dengan tegas menolak aturan
pernikahan sejenis. Manager Nasution
mengatakan lembaganya tidak pernah
membicarakan persoalan legalitas
hubungan sesama jenis. Apalagi perilaku
ini memang sudah bertentangan dengan
landasan hukum di Indonesia. "Komnas
HAM tidak pernah membicarakan legalitas
pernikahan sejenis. Kalau ada yang
mengusulkan, maka saya akan dengan
tegas menolak," (Republik on Line, 3 juli
2015).

Upaya Komnas HAM dalam konteks ini justru bukan tertuju pada legalitas perkawinan itu sendiri tetapi lebih mengarah pada upaya penyembuhan jika pelaku hubungan sejenis terkena penyakit. Tidak ada pembahasan mengenai usulan pernikahan sejenis karena memang di Indonesia tidak akan pernah terbuka peluang memberikannya. Hingga saat ini tidak ada rencana pembahasan legalitas pernikahan sejenis. Walaupun tidak menutup kemungkinan usulan itu bisa muncul.

Undang-undang perkawinan di indonesia merupakan perwujudan dan bentuk komitmen dari segenap bangsa Indonesia dalam rangka membangun Negara Kesatuan Republik 
Indonesia yang mengedepankan nilai-nilai Ketuhanan Yang Maha Esa sebagaimana dimuat dalam konstitusi Indonesia.

Pihak lain yang juga menentang perkawinan sesama jenis datang dari Ketua Komisi VIII DPR RI Saleh Partaonan Daulay. Dalam pandangannya pernikahan sesama jenis tidak boleh dilakukan di Indonesia. Selain menyalahi berbagai norma, pernikahan sesama jenis juga bertentangan dengan aturan undangundang. Hal ini juga sesuai dengan UndangUndang Perkawinan Nomor 1 Tahun 1974, yang mengamanatkan bahwa perkawinan mestinya dilakukan oleh laki-laki dan perempuan. Tidak ada aturan yang memperbolehkan pernikahan sesama jenis, baik norma hukum, norma agama maupun norma sosial masyarakat Indonesia. Selain itu, pandagannya juga menegaskan bahwa pernikahan sesama jenis mengganggu tatanan kehidupan sosial, keyakinan dan nilai-nilai spiritual masyarakat. Sebab, belum ada satu agama pun yang memberikan legalisasi terhadap pernikahan sesama jenis (Republika on Line, Jumat (3/6/2015).

Pandangan tentang perkawinan sesama jenis bahkan juga datang dari Menteri Agama Republik Indonesia, Lukman Hakim Saifuddin. Pernikahan sesama jenis dalam pandaagannya tidak dapat diterima di Indonesia. Sebab, masyarakat Indonesia merupakan warga negara yang religius. Pernikahan adalah bagian dari ibadah. Karenanya, nilai-nilai agama tidak bisa dipisahkan dari sebuah pernikahan.

Selain itu, paradigma perkawinan sesama jenis akhirnya juga keluar dari Ketua Komisi Fatwa MUI KH. Ma'ruf Amin yang dengan tegas menyatakan bahwa pernikahan sejenis adalah haram. Hal ini sebagaimana yang disampaikan beliau dengan pernikahan tersebut sebagai berikut; "Laki-laki sama laki-laki atau perempuan sama perempuan itu kan kaumnya Nabi Luth. Perbuatan ini jelas lebih buruk daripada zina."

Polemik perkawinan sejenis yang menjadi ramai dalam pergulatan pemikiran dan perbincangan di kalangan akademisi selain berangkat dari fenomena di Amerika juga pegiat Hak Asasi Manusia Ade Armando yang konon terinspirasi dari pemikiran-pemikiran Musda Mulia tentang kebebasan manusia dan hak asasi yang perlu mendapat porsinya untuk diperjuangkan. Walaupun tidak mulus dan mendapat kecaman keras berbagai pihak, pemikiran ini terus menjadi diskursus yang panjang di Indonesia. Kecaman itu datang antara lain dari pakar kedokteran jiwa dari Fakultas Kedokteran Universitas Indonesia (FKUI) Prof. Dr. dr. H. Dadang Hawari yang mengangggap bahwa perilaku LGBT itu bukan fitrah atau gen, tapi penyakit. LGBT itu penyimpangan atau kelainan, bisa dikoreksi (disembuhkan) karena bukan dari gen, tapi pengaruh lingkungan, yang penting yang bersangkutan menyadari bahwa apa yang dia lakukan tidak sesuai dengan fitrah. Dalam pandangannya, menghalalkan perkawinan (homoseksual dan lesbian) sebenarnya lebih bersumber dari jiwa yang sakit, emosi yang tidak stabil dan nalar yang sakit. Penyakit homoseksual dan lesbian bisa diobati, kasus homoseksual tidak terjadi dengan sendirinya, melainkan melalui proses perkembangan psikoseksual seseorang, terutama faktor pendidikan keluarga di rumah dan pergaulan sosial. 
Anggota Majlis Tarjih PP Muhammadiyah, Marifat Iman menyampaikan bahwa pernikahan sejenis atas nama hak asasi manusia (HAM) justru melanggar HAM itu sendiri. Pasalnya, HAM yang seharusnya diperjuangkan adalah hak yang sesuai dengan kodrat alam dan digariskan tuhan. Hal ini mengingat manusia telah diciptakan berpasang-pasangan.

Indonesia memang bukan negara agama, tetapi menganut asas Ketuhanan Yang Maha Esa dimana nilai-nilai keagamaan harus dikedepankan, disamping itu budaya timur kita juga menjunjung tinggi etika dan moralitas bangsa, oleh karenanya sudah sejatinya Indonesia melarang pernikahan sesama jenis, bukan saja tidak sesuai dengan HAM di Indonesia yaitu HAM yang adil dan beradab, tetapi juga melampaui keadaban kita sebagai bangsa.

\section{Perkawinan Sejenis Menurut Undang-Undang Perkawinan dan Perspektif Hukum Islam}

\section{a. Perkawinan Sejenis Menurut Undang- Undang Perkawinan di Indonesia}

Hakim Agung Kennedy sebagaimana yang dikutip harian New York Times mengatakan "They ask for equal dignity in the eyes of the law, the constitution grants them that rights". Di detik pembacaan keputusan tersebut, ribuan warga LGBT di seluruh negara bagian Amerika Serikat bergembira, bahkan Presiden Barack Obama mengatakan bahwa keputusan ini mengafirmasi adanya kepercayaan masyarakat Amerika bahwa mereka diperlakukan secara sama di mata hukum. "They ask for equal dignity in the eyes of the law, the constitution grants them that rights" Anthony Kennedy. Keputusan ini tentu sangat bersejarah mengingat Amerika Serikat adalah negara barat terakhir selain Australia yang mengesahkan pernikahan sesama jenis dan berlaku penuh di seluruh negara bagian.

Indonesia memiliki Undang-undang sendiri yaitu dalam Pasal 2 ayat (1) UU Perkawinan dikatakan juga bahwa perkawinan adalah sah apabila dilakukan menurut hukum masing-masing agamanya dan kepercayaannya. Ini berarti selain negara hanya mengenal perkawinan antara wanita dan pria, negara juga mengembalikan lagi hal tersebut kepada agama masing-masing. Mengenai perkawinan yang diakui oleh negara hanyalah perkawinan antara pria dan wanita juga dapat kita lihat dalam Pasal 34 ayat (1) UndangUndang No. 23 Tahun 2006 tentang Administrasi Kependudukan (sering disebut UU Adminduk) beserta penjelasannya dan Pasal 45 ayat (1) Peraturan Daerah Provinsi DKI Jakarta No. 2 Tahun 2011 tentang Pendaftaran Penduduk dan Pencatatan Sipil (Perda DKI Jakarta No. 2/2011 beserta penjelasannya).

Pasal 34 ayat (1) Undang-Undang Administrasi Kependudukan bahwa perkawinan yang sah berdasarkan ketentuan Peraturan Perundang-undangan wajib dilaporkan oleh penduduk kepada instansi pelaksana di tempat terjadinya perkawinan paling lambat 60 (enam puluh) hari sejak tanggal perkawinan. Penjelasan Pasal 34 ayat (1) Undang-Undang Administrasi Kependudukan bahwa yang dimaksud dengan "perkawinan" adalah ikatan lahir batin antara seorang pria dan seorang wanita sebagai suami istri berdasarkan ketentuan peraturan perundangundangan (Undang-Undang Nomor 23 Tahun 2006 tentang Administrasi Kependudukan). 


\section{b. Perkawinan Sejenis dalam Perspektif Hukum Islam}

Sejarah dan buruknya pernikahan sejenis di zaman Nabi Luth a.s. dalam Al-Quran sudah memberikan gambaran jelas bagaima terkutuknya kaum Nabi Luth adalah karena perilaku hoseksua di antara mereka. Hal sebagaimana Al-Qur'an Surah Al A'raf ayat 80-84, menjelaskan:

"Dan (kami juga telah mengutus) Luth (kepada kaumnya). (ingatlah) tatkala Dia berkata kepada mereka: "Mengapa kamu mengerjakan perbuatan faahisyah itu, yang belum pernah dikerjakan oleh seorangpun (di dunia ini) sebelummu?"

Sesungguhnya kamu mendatangi lelaki untuk melepaskan nafsumu (kepada mereka), bukan kepada wanita, malah kamu ini adalah kaum yang melampaui batas.

Jawab kaumnya tidak lain hanya mengatakan: "Usirlah mereka (Luth dan pengikut-pengikutnya) dari kotamu ini; Sesungguhnya mereka adalah orang-orang yang berpura-pura mensucikan diri."

Kemudian Kami selamatkan Dia dan pengikut-pengikutnya kecuali isterinya; Dia Termasuk orang-orang yang tertinggal (dibinasakan).

Dan Kami turunkan kepada mereka hujan (batu); Maka perhatikanlah bagaimana kesudahan orang-orang yang berdosa itu.

Al-Qur'an melarang segala hubungan seks kecuali di dalam ikatan perkawinan antara seorang pria dan seorang wanita. Sebagian besar penikmat homosexsualitas mengklaim bahwa mereka terlahir dengan kecenderungan seks sesama jenis itu. Mereka mengatakan bahwa mereka tidak mempunyai pilihan, "sudah dari sananya". Meskipun asumsi ini masih bisa diperdebatkan di dunia medis, bahkan kalaupun asumsi ini memang benar, Al-Qur'an dengan tegas menolak menjadikannya sebagai pembenaran bagi pecinta sesama jenis. Menurut Amir Syarifuddin, pengurus MUI, menyatakan bahwa praktik homoseksual adalah dosa. Kami umat Islam tidak akan meganggap kaum homoseksualitas sebagai musuh namun kami ingin membuat mereka sadar bahwa apa yang mereka lakukan adalah salah.

\section{KESIMPULAN DAN SARAN}

\section{Kesimpulan}

Pernikahan sejenis atas nama hak asasi manusia (HAM) justru melanggar HAM itu sendiri. Pasalnya, HAM yang seharusnya diperjuangkan adalah hak yang sesuai dengan kodrat alam dan digariskan tuhan yaitu manusia telah diciptakan berpasang-pasangan dan berdasarkan peraturan perundang-undangan di Indonesia perkawinan sesama jenis tidak dapat dilakukan karena menurut hukum perkawinan adalah dilakukan antara seorang pria dan seorang wanita. Sisi lain menegaskan bahwa hukum agama Islam secara tegas melarang perkawinan sesama jenis.

Komnas HAM Indonesia tidak pernah membicarakan persoalan legalitas hukum hubungan sesama jenis, karena perilaku pernikahan sesama jenis bertentangan dengan landasan hukum di Indonesia.

\section{Saran}

Komnas HAM Indonesia sebaiknya mensosialisasikan di media sosial berupa larangan masyarakat yang menyukai sesama jenis apalagi mengarah kepada perkawinan, dan menyampaikan larangan baik secara hukum positif di Indonesia maupun hukum agama dan menyampaikan bahaya terhadap kesehatan bagi yang melakukannya hubungan sesama jenis. 
Kepada masyarakat dihimbau melaporkan kepada yang berwajib ketika mengetahui perilaku warga yang melakukan hubungan sesama jenis (homoseksual dan lesbian), agar warga yang memiliki kelainan perilaku dapat segera dibina dan diobati, karena orang yang menyukai sesama jenis dianggap menderita sakit secara mental.

\section{DAFTAR PUSTAKA}

Al Qur'an Terjemahan Kementerian Agama R.I.

Artikel, Fact Check, Apa Yang Mendasari Legalisasi Pernikahan Sesama Jenis, Akun Selasar.com yang mengecek data-fakta isu, diakses 4 Desember 2011.

Dadang Hawari, Pendekakan Psikoreligi pada Homoseksual.

Departemen Agama R.I., Bahan Penyuluhan Hukum, Tahun 2004.

Majalah Tabligh, Allah Tak Haramkan LGBT, Fatwa Sesat Ade Armando.

Nasution, Manager. Majalah Tabligh, edisi Special Muktamar Ke- 47.

Pernikahan Sejenis, dari Wikipedia Bahasa Indonesia, Ensiklopedia Bebas, Artikel diakses 21 Desember 2015.

Republika.co.id, Jakarta

Undang-Undang Perkawinan Tahun 1974.

Zainal Abidin Abubakar, Kumpulan Peraturan Perundang-undangan Dalam Lingkungan Peradilan Agama, Yayasan Al-Hikmah 1992. 